OPEN ACCESS

Edited and reviewed by: Frontiers in Psychiatry, Frontiers Media SA, Switzerland

*Correspondence: John Darrell Van Horn

jvanhorn@usc.edu

Specialty section: This article was submitted to Child and Adolescent Psychiatry, a section of the journal Frontiers in Psychiatry

Received: 23 May 2018 Accepted: 05 June 2018 Published: 22 June 2018

Citation:

Hull JV, Dokovna LB, Jacokes ZJ, Torgerson CM, Irimia $A$ and Van Horn JD (2018) Corrigendum: Resting-State Functional Connectivity in Autism Spectrum Disorders: A Review. Front. Psychiatry 9:268. doi: 10.3389/fpsyt.2018.00268

\section{Corrigendum: Resting-State Functional Connectivity in Autism Spectrum Disorders: A Review}

\author{
Jocelyn V. Hull, Lisa B. Dokovna, Zachary J. Jacokes, Carinna M. Torgerson, Andrei Irimia \\ and John Darrell Van Horn* for the GENDAAR Research Consortium \\ Laboratory of Neuro Imaging (LONI), The Institute for Neuroimaging and Informatics (INI), Keck School of Medicine of USC, \\ University of Southern California, Los Angeles, CA, United States
}

Keywords: resting state, fMRI, functional connectivity, autism spectrum disorder, developmental brain imaging, neural networks

\section{A corrigendum on}

Resting-State Functional Connectivity in Autism Spectrum Disorders: A Review by Hull, J. V., Jacokes, Z. J., Torgerson, C. M., Irimia, A., and Van Horn, J. D. (2017). Front. Psychiatry 7:205. doi: 10.3389/fpsyt.2016.00205

Due to an unfortunate oversight at the time of final submission of our original article, Ms. Lisa Beth Dokovna, who made important contributions to this article was not included as joint first-author on the authorship list. Rather, she was included in the acknowledgments section. The authors apologize for this error which was an honest mistake and one that they would like to rectify. This correction, however, does not change the scientific conclusions of the original article in any way.

The updated Author Contribution Statement appears below. We also wish to mention the financial support in our Funding Statement. Finally, please also find a corrected Acknowledgments section below to replace the one in place presently.

The original article has been updated.

\section{AUTHOR CONTRIBUTIONS}

JH, LD, and JDVH contributed to the conception, research, and preparation of the manuscript. ZJ, $\mathrm{CT}$, and AI provided critical intellectual input on the narrative and conclusions of the manuscript. ZJ also contributed detailed author proof edits on the final published version of the manuscript. JH and LD serve as joint first authors of this work. All authors provide approval for publication of the content.

\section{FUNDING}

This study was funded by the National Institute of Mental Health, grant 1R01MH100028 (PI: Kevin Pelphrey, subcontract to JDVH). 


\section{ACKNOWLEDGMENTS}

The authors also wish to thank Dr. Kevin Pelphrey for constructive comments on an earlier draft of this article. The authors acknowledge the outstanding members of the USC Mark and Mary Stevens Neuroimaging and Informatics Institute. The GENDAAR Research Consortium includes (in alphabetical order): Elizabeth Aylward, Raphael Bernier, Susan Bookheimer, Mirella Dapretto, Nadine Gaab, Dan Geschwind, Allison Jack, Charles Nelson, Kevin Pelphrey, Matthew State, Pamela Ventola, and Sara Jane Webb.
Conflict of Interest Statement: The authors declare that the research was conducted in the absence of any commercial or financial relationships that could be construed as a potential conflict of interest.

Copyright (c) 2018 Hull, Dokovna, Jacokes, Torgerson, Irimia and Van Horn. This is an open-access article distributed under the terms of the Creative Commons Attribution License (CC BY). The use, distribution or reproduction in other forums is permitted, provided the original author(s) and the copyright owner are credited and that the original publication in this journal is cited, in accordance with accepted academic practice. No use, distribution or reproduction is permitted which does not comply with these terms. 